\title{
Necessary Truth and Grammatical Propositions
}

\author{
HANS-JOHANN GLOCK
}

The topic of this paper is what I call the linguistic doctrine or, keeping in mind Wittgenstein's animadversions to philosophical theories, the linguistic account of necessary propositions. I shall first present a sketch of the linguistic doctrine, and of its two versions-classical conventionalism which maintains that necessary propositions are true by virtue of meaning and Wittgenstein's and Carnap's alternative that they are constitutive of meaning (section I). Next I discuss classical conventionalism and some of the criticisms that have been raised against it by Quine and Wittgenstein (section II). In section III, I turn to Wittgenstein's 'grammatical' version of the linguistic doctrine. My main interest will be to explore in how far it can stand up to the objections of reasonably sympathetic critics like Kalhat. In the final section I return to the question of whether there isn't after all a kernel of truth in classical conventionalism, taking my cue from Schroeder.

\section{The Linguistic Account}

The linguistic account deals with the propositions of logic (e.g. those of the form ' $\sim(p \& \sim p)$ ') and mathematics (e.g. ' $7+5=12$ '), as well as with analytic propositions, broadly conceived. The latter include definitional truths like

(1) All bachelors are unmarried.

The linguistic account is characterized by the following claims:

a) mathematical, logical and analytic propositions are necessary and a priori, contrary to radical empiricists like Mill and Quine;

b) they do not describe or provide information about (a special kind of) mindindependent reality, whether it be abstract entities beyond space and time or the most abstract or general features of physical reality (contra Plato and, Aristotle);

c) they do not explicate mental structures, contrary to the transcendental approach of Kant, neo-Kantianism and the later Husserl;

Phenomenology as Grammar (Ed. Jesús Padilla Gálvez), 63-76.

(C) Ontos Verlag, Frankfurt a. $M$. 
d) they are not synthetic but analytic or conceptual, in that their special (necessary, a priori) status has to be explained by reference to language, and, more specifically, by reference to the meaning of expressions and hence to the way they are used.

The linguistic account faces challenges on several fronts. It has to demarcate necessary, a priori or analytic from contingent, empirical or synthetic propositions; it has to account for the special status of the former; and it has to explain their philosophical relevance. This paper only addresses the second problem. Furthermore, it concentrates on the version of the linguistic account propounded by Wittgenstein in his middle and later period. Finally, it restricts itself to 'analytic propositions', leaving aside logic and mathematics. This means among other things that I shall not attempt to meet the Quinean objection against classic conventionalism, namely that a linguistic account of logic is circular, since logic is required to derive logic from linguistic conventions. ${ }^{1}$

The linguistic account comes in two versions. The first is far better known, since it is associated with logical positivism during its heyday and was popularized by Ayer ${ }^{2}$. According to this position, which I label classical conventionalism, analytic propositions are true by virtue of their meaning, or, more specifically, by virtue of the meaning of their constituent terms. Logical truths are tautologies which are true in virtue of the meaning of the logical constants alone, and analytical truths proper can be reduced to tautologies by substituting synonyms for synonyms. Thus (1) is transformed into "All unmarried men are unmarried", a tautology of the form " $(\mathrm{x})((\mathrm{Fx} \& \mathrm{Gx}) \rightarrow \mathrm{Gx})$ ". This conception of analytic propositions as those that can be derived from logical propositions with the help of definitions is nowadays often referred to as Frege analyticity, ${ }^{3}$ although it goes back at least to Kant. What the logical positivists added is the idea that the truth of both logical propositions and analytic propositions proper is guaranteed by meaning alone and hence by linguistic conventions. Whereas the truth of logical propositions is guaranteed by the meaning of the logical constants that occur in them, the truth of analytic propositions is also guaranteed by the meaning of other constituent terms of those propositions.

\footnotetext{
${ }^{1}$ For my attempts to meet some of the other challenges see Glock 1996; 2003 and 2008. See also Schroeder 2008.

2 Ayer 1971.

${ }^{3}$ E.g. Boghossian 1997.
} 
The second version of the linguistic account was developed by Wittgenstein's reflections on grammatical propositions in the early thirties, and taken up by Carnap's discussion of implicit definitions. Its progenitors have not left us with a neat canonical formulation, but its general outline has been brought to light by recent commentators. ${ }^{4}$ The basic idea is that necessary propositions (alias 'grammatical propositions' (Wittgenstein)) or 'implicit definitions' far from following from meaning, are constitutive of meaning and hence normative.

Classic conventionalism can be seen as arising from the following argument:

$\mathrm{P}_{1} \quad$ In the case of analytic propositions, meaning suffices for truth

$\mathrm{P}_{2} \quad$ Linguistic rules/conventions suffice for meaning

C In the case of analytic propositions, linguistic rules / conventions suffice for truth

The argument is valid. Furthermore, there are good reasons for accepting $\mathrm{P}_{2}{ }^{6}$ But ever since the $1930 \mathrm{~s}, \mathrm{P}_{1}$ has been rejected by critics of classical conventionalism as diverse as Wittgenstein, Waismann and Quine.

They question the very idea that some propositions are true solely in virtue of the meaning of their constituents, independently of the world. As Waismann ${ }^{7}$ pointed out, the phrase "true by virtue of meaning" is prima facie puzzling, since it is unclear how a proposition could follow from a meaning rather than from another proposition. Quine associated the phrase with the "myth of a museum", Wittgenstein with the picture of "meaning-bodies". What they condemn under these titles is the idea that there are meanings-abstract entities or mental processes--which coerce us (either psychologically or rationally) to hold on to analytic propositions, come what may.

In fact, the proponents of the linguistic theory were never committed to such a Platonist or mentalist myth. Without it, however, the idea of truth by virtue of meaning boils down to the claim that necessary propositions are true

\footnotetext{
${ }^{4}$ See Baker/Hacker 1985, ch. VIII; Coffa 1990.

${ }^{5}$ Carnap 1937.

${ }^{6}$ See Wittgenstein $B B, 1958,27-8$.

${ }^{7}$ Waismann 1968, 124-5.

${ }^{8}$ Waismann 1969, 27, see 19.

${ }^{9}$ Wittgenstein $P G, 1974,54-8$.
} 
by virtue of definition: they follow from the definitions, or, more loosely, the explanations, of their constituents.

Wittgenstein rejected even this seemingly innocuous idea. But his animadversions are uncompelling ${ }^{10}$. Wittgenstein challenged the idea that the tautologies and the associated rules of inference follow from the truth-tabular definitions of the logical constants. Rules of inference, he informs us, determine the meaning of the logical constants, rather than proceeding from them. Whether a specific transformation of symbols is licensed or not is one aspect of the correct use and hence of the meaning of the terms involved. That we use ' $p=\sim \sim p$ ' as a rule of inference contributes to the meaning of ' $\sim$ '. Without that rule the sign would not have the meaning it has. And if the rule were changed, if we accepted instead ' $\sim p=\sim p$ ', the meaning of ' $\sim$ ' would change correspondingly. Accordingly, the rules of inference cannot correspond or fail to correspond to the meaning of e.g. negation. Someone who passes, let us say, from ' $\sim p$ ' to ' $\sim p$ ' does not follow a false rule of negation, but has given a different meaning to ' $\sim$ '.

However, to say that ' $\sim p=p$ ' follows from the truth-tabular definition of ' $\sim$ ' can be understood innocuously as the contrapositive of Wittgenstein's own claim. From Wittgenstein's claim that if we alter the rule we alter the meaning it follows that if we do not alter the meaning, we get the rule. Furthermore, although we could use ' $\sim$ ' according to either ' $\sim p=p$ ' or ' $\sim \sim p=\sim p$ ', it would be inconsistent to combine our truth-tabular explanation of it with the second rule. For in that case we would say that the truth-table has been misunderstood-as every logic-tutor will confirm. By Wittgenstein's own lights, the truth-tabular explanation is a rule, and to accept ' $\sim \sim p=\sim p$ ' is a criterion for having misunderstood that rule, because one is not applying the same operation--that of reversing the truth-value--to $\sim \mathrm{p}$ that has been applied to $p$.

Wittgenstein replies 'Who says what "the same thing" is'. ${ }^{12}$ What he has in mind is that the rule follows from the explanation only if it is understood that in the truth-table the place of $p$ can be taken by ' $\sim p$ ', i.e. that in applying negation to ' $\sim p$ ' we reverse the truth-value of a proposition rather than operating on an operation. Wittgenstein illustrates the difference through

\footnotetext{
${ }^{10}$ Glock 1996a, 239-41; cp. Baker/Hacker 1985, 312-8.

${ }^{11}$ Wittgenstein PU, 1953, 147n; Wittgenstein LFM, 1976, 398.

${ }^{12}$ Wittgenstein LFM, 1976, 180.
} 
brackets: the first—and standard--option corresponds to ' $\sim(\sim p)$ ', the second to ' $(\sim \sim) p$ '. Accordingly, ' $\sim p=p$ ' is not determined by the truth-table definition alone, but only in conjunction with this second rule. Since there is no comparable rule in natural languages, nothing determines how to understand 'I ain't done nothing'. ${ }^{13}$ But this is not a general objection to the idea that explanations - if necessary in combination--can render a proposition true. 'The rules/grammatical propositions determine the meaning' is as wrong as 'The meaning determines the rules/grammatical propositions'. Understanding the truth-tabular explanation and acknowledging ' $\sim \sim p=p$ ' are simply internally related aspects of one and the same practice of using ' $\sim$ '. The truth-table would mean something different in a practice in which the rule is rejected. Both are simply two different rules which make up our practice.

Another qualm about the very idea of truth by virtue of meaning or convention goes back to C.I. Lewis ${ }^{14}$ and C. Lewy ${ }^{15}$. It seems that for any sentence $s, s$ is true iff for some $p, s$ says that $p$ and $p$. All that conventions do is to determine what a sentence says; whether what it says is true is another question, to which linguistic conventions are irrelevant. Therefore, a sentence cannot owe its truth-value exclusively to meaning or conventions ${ }^{16}$. A related worry has exercised some Wittgensteinians. What could it mean for a convention to create a truth? Of course, we can choose to assume that a certain proposition is true, in the course of constructing hypotheses, or for the sake of argument. But this does not render that proposition true. In the sense in which, for example, the fact that the cat is on the mat might be said to render true the statement that the cat is on the mat, conventions cannot be said to render anything true. The only truths conventions could 'create' are truths such as 'In 1795 France adopted the metric system', which are precisely not true by convention ${ }^{17}$.

\footnotetext{
${ }^{13}$ Wittgenstein LFM, 1976, 184.

${ }^{14}$ Lewis 1946.

${ }^{15}$ Lewy 1976.

${ }^{16}$ Boghossian 1997, 335-7.

${ }^{17}$ Baker/Hacker 1985, 234; Glock 2003, 158-9.
} 


\section{Necessary Propositions and Grammatical Rules}

What conventions can do, however, is to establish rules. Thus we can remove a sentence from the scope of empirical refutation by using it normatively rather than descriptively. But in that case we have not created a truth but adopted what Wittgenstein calls a 'norm of representation'.

Like the logical positivists, Wittgenstein seeks to preserve a connection between (1) and the meaning of the word 'bachelor'. Verifying (1) requires attendance not to the marital status of men, but to the meaning of 'bachelor' and 'unmarried'. By the same token, rejection of (1) betokens linguistic misunderstanding rather than factual ignorance. Unlike the logical positivists, Wittgenstein denies that (1) follows from the meaning of its constituents; instead he maintains that (1) is partly constitutive of that meaning. According to Wittgenstein, (1) is a 'grammatical proposition'. That is to say, it standardly expresses a rule for the correct use of at least one of those constituents (what Wittgenstein also calls a 'norm of representation'), and thereby determines their meaning instead of following from it. By the same token, (1) has a normative status: it can be used to explain 'bachelor', and to criticize or justify one's use of that term. It also draws a line between meaningful uses of that term and nonsense like 'There is a married bachelor at the party'.

For Wittgenstein, this normative role of (1) explains its necessity. (1) cannot possibly be refuted by the facts, simply because no sentence contradicting it counts as a meaningful description of reality which is even in the running for stating a fact. In English, no combination of words which contravenes (1) is truth-apt, i.e. counts as a statement or proposition that is even in the running for being true. At the same time, according to Wittgenstein language is 'autonomous' and grammatical rules like (1) are 'arbitrary'. They do not mirror putative essences in reality, but constitute what might be called the essence or nature of bachelors. By the same token, they have the status of conventions. Although it is not up to individuals to alter grammatical rules, and although there can be reasons for adopting one grammar rather than another, we can in principle adopt different rules, and thereby accord a necessary alias normative status on different propositions. 
Wittgenstein's normativist account of necessity faces an immediate objection first formulated by Waismann ${ }^{18}$ : unlike necessary propositions, grammatical rules cannot be true or false. As it stands, however, this objection is not compelling. We do predicate truth of paradigmatic expressions of rules such as

(2) The chess-king moves one square at a time

But this means no more than that the rule to move the chess king one square at a time is in force ${ }^{19}$.

This defence of the normativist position has recently been criticized by Kalhat $^{20}$. According to him, such 'normative truth' cannot account for crucial features of necessary propositions. For one thing, they can occur in conditional statements such as

(3) If all bachelors are unmarried and Kant is a bachelor, then Kant is unmarried

If (1) were normatively rather than factually true, however, (3) would be, in the words of von Wright, 'a logical monster'. Kalhat considers the response that one can mix factual with normative truth without creating logical monsters, as in

(4) If the chess-king moves one square at a time, then the move you have just made will not be accepted by the community of chess players

He objects, however, that this is elliptical for

(5) If [The rule according to which the chess-king moves one square at a time is in force] then [The move you have just made will not be allowed by the community of chess players]

We cannot treat (3) in an analogous fashion, Kalhat suggests. For that would deliver

(6) If [the rule according to which the word 'bachelor' applies to men who are unmarried, is in force] and [Kant is a bachelor] then [Kant is unmarried]

And this would render the conditional contingent and would 'allow for a possibility that is otherwise (rightly) blocked', namely that 'while Kant is a bachelor, we cannot infer that Kant is unmarried because the proposition

\footnotetext{
${ }^{18}$ Waismann 1968, 66-7, 136-7.

${ }^{19}$ see Glock 2003, 163-4.

${ }^{20}$ Kalhat 2008.
} 
'The rule according to which the word "bachelor" applies to men who are unmarried, is in force' is false ${ }^{21}$.

Unlike Kalhat, I do not regard this as an absurdity. If it is not a rule for the use of 'bachelor' that the term applies exclusively to unmarried men, then we can indeed no longer infer from the fact that 'bachelor' applies to Kant that 'unmarried' applies to Kant. (3) is a tautology quite independently of the conceptual connection between 'bachelor' and 'unmarried', and hence independently of the modal status of (1). That status reveals itself precisely in the fact that we do not need an additional piece of information to move from 'Kant is a bachelor' to 'Kant is unmarried'. By contrast, we would need an additional factual premises to move, e.g., from 'Kant is a bachelor' to 'Kant is unhygienic', in our case the premise 'All bachelors are unhygienic'.

As a result, Kalhat's first line of attack boils down to two objections. The first is that statements like (3) would be 'logical monsters' rather than tautologies if they mixed factual and normative propositions. But it remains to be shown that this fear is more than superstition. Why shouldn't one preserve the distinction between factual and normative propositions, while recognizing that the common applicability of 'true' signals, among other things, that the two can be combined e.g. in conditionals like (3)?

The second objection which emerges from Kalhat's discussion of normative truth is that Wittgenstein's account cannot do justice to the necessity of propositions like (1). Normative truth attaches to rules (or ruleformulations) that are in force. Furthermore, since grammatical rules are arbitrary, they might not be in force. Accordingly, 'normatively construed, the truth predicate could fail to apply to necessary propositions (in those cases where qua rules they fail to be in force). Yet insofar as these propositions are necessary, the truth predicate simply could not have failed to apply to them. In calling them "necessary" we mean precisely that they could not possibly fail to be true. They could not possibly fail to be true whatever their truth amounts to'.22

This passage eloquently expresses the realist sentiment concerning necessary propositions. As a criticism of Wittgenstein, however, it begs the

\footnotetext{
${ }^{21}$ Kalhat 2008, 9-11.

${ }^{22}$ Kalhat 2008, 12.
} 
question. For Wittgenstein challenges that sentiment by maintaining that the idiom of 'necessarily true' disguises the actual role of the propositions concerned. He grants that in calling propositions like (1) necessary or necessarily true, we accord them a special status. But he claims that this special status is not simply being true plus being true eternally or in all possible worlds. Rather, it means that we would not count anything as refuting a necessary proposition. Not their truth, but rather their necessity depends on this normative status. The way we use 'bachelor' has no immediate impact on the marital status of people. But it can have an impact on whether the term 'married bachelor' can meaningfully be applied to someone. Accordingly, certain propositions can lose their normative status, the status to which their necessity boils down to.

That may sound implausible. But there are pertinent examples that suggest otherwise ${ }^{23}$. Statements that were once regarded as paradigms of necessary truth, such as Euclid's $5^{\text {th }}$ axiom or the claim that there cannot be negative numbers have not just been stripped of their necessary status, they have been rejected altogether. Kalhat would presumably regard this as a merely epistemological complication. We can be mistaken as to what truths hold in all possible worlds. But even if the progress of mathematics involved increased knowledge of a modal realm, this would not explain all the cases in which necessary propositions have been abandoned. If it were a truth about that realm that there are negative as well as positive numbers, it would be one so basic that it should have been obvious to mathematical geniuses like Euclid or Eudoxos. The progress concerning negative numbers consists not in a new discovery about an abstract reality, but in the realization of the power of a novel system of calculation. That system is alien to ancient modes of thought, yet immediately attractive to a physics which revolves around acceleration vs. deceleration and a financial system which includes debt was well as credit.

Another objection to the normativist view also goes back to Waismann. Unlike linguistic rules, analytic propositions are about vixens, colours, and bachelors, etc., not about words. A standard response is that Wittgenstein's notion of a grammatical proposition concerns function rather than linguistic form. Accordingly, a grammatical proposition like (1) can both be about bachelors and function as a rule for the use of words.

${ }^{23}$ see Baker/Hacker 1985, ch. VIII. 
Kalhat has responded that a necessary statement cannot both be about, e.g., numbers and colours and be a rule for the use of words. A look at the rules of chess suggests otherwise, however. (2) is both about the chess-king and a rule for the use of the chess king. Kalhat might question the analogy. For in the chess case, the rule guides the use of what it is about. In the linguistic case, by contrast, the rule guides words, yet it is supposed to be about what those words denote. Wittgenstein would respond, however, that the sense in which numerals like ' 2 ' denote numbers is a special one. Numbers are what numerals denote or signify, but the meaning of numerals is given not by a mental pointing at entities beyond space and time, but by specifying the rules for their use.

Kalhat next contends that if a grammatical proposition like (1) were constitutive of the meaning of 'bachelor', then it should in some sense be about that word ${ }^{24}$. I don't see why this should have to be the case. The socalled central paragraphs are constitutive of the constitution of the Federal Republic of Germany not just in the mereological sense, but also in the sense that they define that particular body of laws irrespective of its overall composition at any given time. They are explicitly specified to be unalterable, and hence no legal codex that lacks them can be that constitution. And yet these paragraphs are not about the constitution of the Federal Republic of Germany. Furthermore, there is a sense in which (1) is about the word 'bachelor': it is standardly used as rule for the use of that word. If you say 'I met a married bachelor', I can correct and inform you by uttering (11).

Kalhat also maintains that as a grammatical rule (1) would have to be equivalent to

(7) The English word 'bachelor' applies to all and only unmarried men.

This, he protests, is wrong, since unlike (1), (7) is a meta-linguistic statement and hence contingent.

Admittedly, (7) can be used as an empirical proposition, as what von Wright calls a 'norm proposition'. ${ }^{25}$ In that case it is a statement to the effect that a community (in our case the community of Anglophones) follows certain linguistic rules (in our case the rule of applying 'mare' only to female

\footnotetext{
${ }^{24}$ Kalhat 2008, 14.

25 von Wright 1963, viii.
} 
horses and accepting its application to all and only female horses). But (7) can also be used normatively, as the expression of a constitutive rule of English. In that case, it is not an empirical proposition which is falsified e.g. by someone who applies 'mare' to male horses, or female foxes, or nightmares. Its dependence on the contingent behaviour of Anglophones is indirect: if everybody violated the rule and nobody accepted corrections of such violations, then the rule would no longer be in force. Certain contingent regularities are part of the framework for our linguistic activities, as Wittgenstein stressed.

\section{Conclusion}

In Section II, I indicated that there are reasons for rejecting classical conventionalism not just from a Quinean but also from a Witttgensteinian perspective. At least one Wittgensteinian begs to differ, however. Schroeder ${ }^{26}$ makes out a clear and prima facie attractive case for insisting that there is nothing mysterious about the idea of truth in virtue of meanings or conventions. What we need to do is to move away from the general schemas invoked by the Lewis-Lewy objection, he insists, and instead attend to suitable specific examples. Thus:

(8) 'A tandem' means: a bicycle with two seats

is true because the word 'tandem' does mean a bicycle with two seats. The same goes for the definitional truth

(9) A tandem is a bicycle with two seats

which has the same function and can also be verified simply by looking up the meaning of 'tandem' in a dictionary (assuming standard meaning for the other components).

Schroeder also addresses Kalhat's worry that a linguistic account turns necessary propositions into mere stipulations without a truth-value. This holds true of original stipulations which 'give a meaning' to expressions, he concedes, but not of propositions like (9) which 'report correctly what meaning ["tandem"] has in English'. In this context Schroeder takes me to task for maintaining (in line with Wittgenstein, incidentally) that analytic-

${ }^{26}$ Schroeder 2006, 242-3; Schroeder 2008. 
cum-grammatical propositions partly determine or constitute the meaning of the words involved. "The meaning of the English word "tandem" is completely independent of what I may say: What "partly constitutes" the meaning of the word "tandem" is not the statement (16), but the linguistic convention that such a statement reflects'.

In one respect, this is a misunderstanding of the Wittgensteinian position. It makes meaning dependent not on what individual speakers 'may say', but on whether we use certain sentences as standards of correctness, rather than as factual statements. To that extent, there is no real conflict, even though Schroeder's reminder of the dependency of analytic propositions on a convention is salutary. In another respect, the term 'reflect' conceals precisely the difficulty highlighted by Kalhat. Schroeder himself spells it out by saying that analytic propositions 'describe' games or 'report correctly' what meaning expressions have in a particular language. In that case, however, it would seem that these propositions must be empirical and contingent rather than necessary.

A way out of this particular quandary has already been intimated in my discussion of Wittgenstein's animadversions against meanin-bodies. Unlike norm propositions, analytic propositions do not just talk about a practice, they are part of it. They are partly constitutive of meaning rather than simply recording or following from it. That is to say, they are normative statements which form part of practice that, in its entirety, determines the meaning of the word. Both the applications and the explanations of words by individual speakers are responsible to this established practice (unless they deliberately diverge from it and thereby stipulate a new meaning for a word). Analytic propositions are 'normatively true' in that they express--rather than describe or state the existence of--conventions that are actually in place in a particular linguistic community. At the same time, those conventions would not exist if the community adopted different conventions, that is, if it adopted different explanations or consistently tolerated behaviour at odds with the old one.

In conclusion, there is not irreconcilable conflict between the following two ideas. First, necessary propositions have a normative status and are an essential part of the practice that constitutes the meaning of our words. Secondly, they are true by virtue of practice, i.e. by virtue of annunciating, instead of describing, the norms which govern and structure that practice. 
That the two ideas can be made to cohere does not mean that they are true, either jointly or individually. But it is a starting-point for a more comprehensive defence. ${ }^{27}$

\section{Bibliography}

Ayer, A. J., 1971: Language, Truth and Logic, Penguin, Harmondsworth.

Baker, G. P. and P.M.S. Hacker, 1985: Wittgenstein: Rules, Grammar and Necessity, Blackwell, Oxford.

Boghossian, P., 1997: Analyticity, in B. Hale, B. and C. Wright (Eds.) A Companion to the Philosophy of Language, Blackwell Publishers Ltd, Oxford, 1997, 331-68.

Carnap, R., 1937: The Logical Syntax of Language, (German edn. 1934), K. Paul Trench, London.

Coffa, A., 1991: The Semantic Tradition, from Kant to Carnap: To the Vienna Station, Cambridge University Press, Cambridge.

Glock, H. J., 1996: Necessity and Normativity, in: H. Sluga / D. Stern (Eds.), The Cambridge Companion to Wittgenstein, Cambridge University Press, Cambridge, 198-225.

Glock, H. J., 2003: Quine and Davidson on Language, Thought and Reality, Cambridge University Press, Cambridge.

Glock, H. J., 2008: Necessity and Language, Philosophical Investigations, 31, 24-47.

Kalhat, J. 2008: Has the Later Wittgenstein accounted for Necessity?, Philosophical Investigations, 31, 1-23.

Lewis, C.I., 1946: An Analysis of Knowledge and Valuation, The Open Court Publishing Company, La Salle, Ill.

Lewy, C., 1976: Meaning and Modality, Cambridge University Press, Cambridge.

Quine, W.V., 1969: Ontological Relativity and Other Essays, Columbia University Press, New York.

Schroeder, S., 2006: Wittgeinstein. The Way Out of the Fly-Bottle, Polity, Cambridge.

Schroeder, S., 2009: Analytic Truths and Grammatical Propositions, in H. J. Glock \& J. Hyman (eds.), Wittgenstein and Analytic Philosophy, Oxford.

Waismann, F., 1968: How I See Philosophy, St. Martin's Press, New York.

\footnotetext{
${ }^{27}$ For comments on previous versions of this material I am grateful to John Hyman, Javier Kalhat and Severin Schroeder, as well as to audiences at Nettelbeck and Toledo.
} 
Wittgenstein, L., 1953: Philosophical Investigations, (Trans, by G.E.M. Anscombe), England: Blackwell, Oxford.

Wittgenstein, L., 1958: The Blue and Brown Books, Blackwell Publishing Ltd, Oxford.

Wittgenstein, L., 1974: Philosophical Grammar, (R. Rhees (Ed.). A. Kenny (Trans.)), Blackwell, Oxford.

Wittgenstein, L., 1976: Wittgenstein's Lectures on the Foundations of Mathematics, Cambridge 1939, Cornell University Press, Diamond, Ithaca, NY.

von Wright, G.H., 1963: Norm and Action, Routledge \& Kegan Paul, London. 